\title{
On the Right to Science: Recommendations of Selection Criteria for IMIA Scientific Meetings
}

\author{
Christoph U. Lehmann', Elizabeth Borycki ${ }^{2}$, Kyung-Hee Cho ${ }^{3}$, Amado Espinosa ${ }^{3}$, \\ Antoine Geissbuhler ${ }^{4}$, Elaine Huesing ${ }^{5}$, Petter Hurlen ${ }^{6}$, Michio Kimura ${ }^{7}$, \\ Ghislain Kovematchoua Tchuitcheu ${ }^{2}$, Andre Kushniruk', Christian Lovis ${ }^{2}$, Daniel Luna ${ }^{2}$, \\ Anne Moen ${ }^{3}$, Hyeoun-Ae Park', Brigitte Séroussi', Marcelo L. Silva ${ }^{2}$, Hiroshi Takeda ${ }^{7}$, \\ Patrick Weber ${ }^{2}$, Johanna Westbrook ${ }^{8}$, Sabine Koch ${ }^{9}$ \\ 1 IMIA President \\ 2 IMIA Vice-President \\ 3 Past IMIA Vice-President \\ 4 IMIA Past-President \\ 5 IMIACEO \\ 6 IMIA Secretary \\ 7 IMIA Board Member \\ 8 IMIA Treasurer \\ 9 IMIA President Elect
}

\section{Summary \\ The International Medical Informatics Association (IMIA), a non-governmental, not-for-profit, global organization promoting health and biomedical informatics, is committed to the right of communities/populations and individuals to science, comprised of three separate constituent rights: 1) the right to participate in science, 2) the right to benefit from science, and 3) the right to benefit from a person's own contribution to science or inventions. As such, IMIA provides a global platform where scientists, researchers, health information users, vendors, developers, consultants, health care consumers, and suppliers can meet in an environment of cooperation and sharing. In the context of IMIA's conferences, the IMIA board has discussed and identified the important central factors, which are essential considerations to host a scientific meeting. These factors will be used to help vet future contenders applying for the honor to host an IMIA conference: Reasonable safety and security, commitment by the host member society, freedom of travel, scientific freedom, and freedom from discrimination.}

\section{Keywords}

Scientific freedom, biomedical informatics, conference, conference planning, right to science

Yearb Med Inform 2019:11-3

http://dx.doi.org/10.1055/s-0039-1677924
The International Medical Informatics Association (IMIA), an 'association of member associations' and a non-governmental, notfor-profit global organization for health and biomedical informatics, bridges visions/ gaps by bringing together constituent organizations and their members. Inherently, one of IMIA's roles is to provide a global platform where scientists, researchers, health information users, vendors, developers, consultants, health care consumers, and suppliers can meet freely in an environment of cooperation and sharing. In this role, IMIA is committed to scientific freedom as defined in its vision and mission statements [1]. IMIA places scientific freedom as a central value enforcing certain expectations on its member associations that engage in the process of hosting any of IMIA's conferences and meetings. This guidance by the IMIA Board of Directors attempts to identify and codify these expectations that should be met by member associations to guarantee a successful conference and protect scientific freedom at IMIA's conferences. The resulting recommendations aim to aid in the selection process for conference hosts.

\section{Right to Science}

Scientific freedom and human rights are codified in the International Covenant on Civil and Political Rights, a multilateral treaty that has been signed and ratified by 171 countries [2], many of whom are home to IMIA Society Members. The treaty establishes "individual liberty, in the form of the freedoms of movement, thought, conscience and religion, speech, association and assembly, family rights, the right to a nationality, and the right to privacy" [3]. In the International Covenant on Economic, Social and Cultural Rights [4], the United Nations established "1. The right of everyone: (a) to take part in cultural life; (b) to enjoy the benefits of scientific progress and its applications; (c) to benefit from the protection of moral and material interests resulting from any scientific, literary or artistic production of which he is the author." The countries that signed the agreement are committed to "take the steps necessary for the conservation, development and dissemination of science and culture" and to "respect the freedom indispensable for scientific research and creative activity." The right to science is comprised of three separate 
constituent rights: 1) the right to participate in science, 2) the right to benefit from science, and 3) the right to benefit from a person's own contribution to science or inventions.

A UN Special Report on Human Rights delineates the rights to "(a) access by everyone without discrimination to the benefits of science and its application, including scientific knowledge; (b) opportunities for all to contribute to the scientific enterprise and freedom indispensable for scientific research; (c) participation of individuals and communities in decision-making and the related right to information; and (d) an enabling environment fostering the conservation, development and diffusion of science and technology" [5].

IMIA is committed to the Right to Science as it applies to the area of Biomedical and Health Informatics. IMIA supports the right to participate in science by encouraging capacity building in health sciences and by providing accreditation of biomedical and health informatics programs [6]. IMIA must continue to support this right to benefit from science and "seeks to grow and nurture a collaborative global Biomedical and Health Informatics community that encourages and supports international initiatives to improve health for all' [7].

\section{Conferences}

IMIA's largest contribution to the scientific community is the organization of scientific conferences including its flagship international informatics meeting MedInfo, the World Congress of Medical and Health Informatics, where research and science are shared to permit improved health and quality of life for all.

The central factors which are essential considerations for a successful scientific conference include safety and security, commitment by the host member society, freedom of travel, scientific freedom, and freedom from discrimination.

\section{Safety and Security}

Participants of IMIA conferences have a reasonable expectation that their life, liberty, and well-being, as well as their personal property are secure when traveling to the conference. While no conference venue can guarantee complete safety and security, participants at IMIA conferences must have a reasonable degree of assurance that they will not fall victim to crime, be arrested without cause, be exposed to armed conflicts, or subject to injury. Consequently, conference venues should strive for high standards in crime prevention and public safety.

\section{Commitment by the Host Member Society}

The success of any IMIA conference is connected to the commitment and involvement of the host biomedical informatics member society. The host member society must be an active and involved IMIA member and must be vested in creating an environment that encourages knowledge sharing and education. Together with the Scientific Program Committee (SPC) and the local organizing committee (LOC), the host member society must be committed to creating a scientific and educational program that attracts members from IMIA societies from all over the world. The LOC should pay attention to providing a cultural program that encourages conference attendees to learn about the host member's culture and its customs. The ability to understand our hosts better will be critical in fostering international openness and collaboration and will forge stronger bonds among member societies.

The host member society must further assure that IMIA can conduct its business during the conference including and not limited to meetings of the Board of Directors, General Assembly, Working Groups, and the International Academy of Health Sciences Informatics.

\section{Freedom of Travel}

One of the basic pillars of conducting an international, scientific meeting is the requirement that interested scientists from all over the globe must be able to attend. While a visa may be required to attend a conference, there has to be however the absence of discrimination of whole groups of people to participate at an IMIA conference. Travel bans based on religious, ideological, or political reasons are counter to the scientific rights and make a member society less likely to be able to serve as the host to an IMIA conference as all IMIA members must have the ability to travel to the conference unfettered.

\section{Scientific Freedom}

One of the aspects of the right to science is the ability to participate and to exchange scientific knowledge without censorship or fear of repression. Ideologic, dogmatic, religious, or political limits on meetings of scientists for political and ideological reasons are incompatible with the right to science principle. Any local laws or regulatory matters that ban or alter the discussion of scientific topics lower the chance of having a successful bid.

The principle of benefiting from one's own contribution to science implies that a scientist must have the ability to attribute scientific research in a manner that the scientist prefers. This means that, for example, a member association that cannot allow a scientist to identify him/her-self, i.e. his/her name, laboratory, university, town, affiliation, or origin will be less likely to succeed in the conference bid process or serve as a host member association to an IMIA conference.

Scientific freedom also requires that the SPC maintains control over final decisions and approval of the content of the scientific program and the conference proceedings [8], and that IMIA is able to conduct its ongoing business activities at the conference. A member association from a region with policies that do not allow for IMIA business meetings or activities that are required by IMIA will be prioritized lower for conference bids.

\section{Freedom from Discrimination}

IMIA supports a culture of collaboration and inclusion regardless of race and ethnicity, religion, gender identity, including transgender status, sexual orientation, or political 
ideology. IMIA conference attendees expect a culture of mutual respect and freedom from being diminished for their beliefs. A meeting conducted with respect will increase satisfaction and engagement, reduce stress for attendees, improve knowledge sharing, and drive attendance. With changing conference hosts, IMIA conference attendees have expressed appreciation for the opportunity to learn more about different people, religions, cultures, and thoughts. A member association from a region that discriminates (denial of services, denial of required support for visa applications, harassment, defamation) based on these criteria may not be a suitable host member association for an IMIA conference.

\section{Bidding for Conferences}

The member society bidding for IMIA sponsored conference organization should follow the recommendations proposed here. If some recommendation is unreachable, the reasons should be discussed in detail. The bid will be presented to the general assembly with a focus on the missing elements, where the selection of the hosting member society will require two thirds of the full members.

\section{Conclusion}

IMIA is committed to the principle of right to science. This right includes the exchange of knowledge that can benefit patients across the globe. Thus IMIA through its board, CEO, and Vice President for MedInfo proposes to vet future contenders to be shortlisted for the honor to host an IMIA conference based on the principles of the right to science and the five conditions of safety and security, commitment by the host member society, freedom of travel, scientific freedom, and freedom from discrimination.

\section{References}

1. IMIA. Welcome to IMIA. Available online at http:// imia-medinfo.org/wp/. (Last accessed 7/8/2018)

2. United Nations. International Covenant on Civil and Political Rights. Available online at https:// treaties.un.org/doc/publication/unts/volume $\% 20$ 999/volume-999-i-14668-english.pdf. (Last accessed 7/8/2018)

3. Wikipedia. International Covenant on Civil and Political Rights. Available online at https://en.wikipedia.org/wiki/International_Covenant_on_Civil_and_Political_Rights. (Last accessed 7/8/2018)

4. United Nations. International Covenant on Economic, Social and Cultural Rights. Available online at https://treaties.un.org/doc/Treaties/1976/01/19760103\%2009-57\%20PM/Ch_ IV_03.pdf. (Last accessed 7/8/2018)

5. United Nations Office of the High Commissioner. 2012 The right to benefit from scientific progress and its applications. Available online at https:// www.ohchr.org/EN/Issues/CulturalRights/Pages/ benefitfromscientificprogress.aspx. (Last accessed $7 / 15 / 2018)$

6. International Medical Informatics association. IMIA Accreditation Procedure. Available online at https://imia-medinfo.org/wp/imia-accreditation-procedure/. (Last accessed 12/29/2018)

7. International Medical Informatics Association. Welcome to IMIA. Available online at https:// imia-medinfo.org/wp/ (Last accessed 12/30/2018)

8. Lehmann CU. A message from the Editorial Desk. Stud Health Technol Inform. 2013;192:vi. PubMed PMID: 23920503. 